\title{
LAS TRADUCCIONES CHECAS DEL JUDEOESPAÑOL: TRADUCTOR COMO HISTORIADOR
}

\author{
Martina KUTKOVÁ \\ Universidad Carolina, Praga
}

\begin{abstract}
En): In 2008, the Israeli authorities approved the establishment of the National Academy for Judeo-Spanish, which was motivated by the agreement of the Spanish and Israeli academics. The Academy, as a part of the RAE, shall devote itself to the preservation of the JudeoSpanish language that presents not only Jewish linguistic patrimony but also the Hispanic one. In the Czech context, a few graduate linguistic works referred to the Judeo-Spanish language. However, none of them reflected Judeo-Spanish texts in the Czech context, we lack monographs dedicated to the translation issues of such documents. The topic presents an empty space in the context of the history of Czech translations from the Spanish literature. This means that investigation of the matter requires a hardworking research in archives, both in specialized institutions and in personal heritage. Taking into account the international interest in the topic, opening an investigation related to Judeo-Spanish in the Czech context may present a contribution to the progress of the Czech Hispanic Studies as well as to Translation Studies.
\end{abstract}

Resumen (Es): En 2018 aprobaron en el Estado de Israel la creación de la Academia Nacional del Judeoespañol cuyo establecimiento surgió del acuerdo entre los académicos tanto israelíes como españoles. Dicha Academia como parte de la RAE se debería dirigir a la preservación de la lengua judeoespañola como una herencia lingüística y cultural no solamente judía sino también hispana. En el territorio checo se han referido al idioma judeoespañol varios trabajos lingüísticos de graduados. Ninguno, sin embargo, ha reflexionado los textos judeoespañoles en el contexto checo, hay una falta completa de monografías que se dedicaran a la problemática de traducción de aquellos textos. El tema presenta un vacío en el contexto de la historia de las traducciones checas de la literatura española y la investigación del tema, por lo tanto, requiere un trabajo diligente de archivo, no solamente en instituciones especializadas, sino también en herencias personales. Considerando la situación internacional mencionada, es muy actual abrir una investigación del judeoespañol en el contexto checo que podría presentar una aportación tanto al desarrollo de la hispanística checa como a la traductología.

Keywords (En): Czech Translation Studies; History of Translation; Judeo-Spanish; Ladino; marginal languages

Palabras claves (Es): Historia de traducción; judeoespañol; ladino; lenguas marginadas; traductología checa

\section{Introducción}

El judeoespañol, ladino, judezmo o espaniol es uno de los idiomas usados por el pueblo judío que nació en la Península Ibérica antes del año 1492. Ya en el siglo XII surgió en la Península una necesidad de traducir los textos sagrados hebreos y arameos a una lengua comprensible para los judíos de entonces. Había que ladinar, es decir, traducir al idioma romance. Nació, por lo tanto, un sistema lingüístico que fue a pie de las letras hebreas y les asignó un equivalente exacto en la lengua meta. Como no es posible cambiar los textos sagrados, tampoco se pueden modificar las 
traducciones. Así ladino conserva el español medieval y representa «un museo vivo de la historia española» (GARCIA, 2007: 77). A pesar de esto, como ya viene mencionado, la lengua romance de los vecinos no judíos representaba el idioma comprensible y usado en la comunicación cotidiana, aunque con ciertas modificaciones fonéticas y lexicales debidos a las diferencias culturales y religiosas (GARCIA, 2007: 79).

Tras la expulsión, los judíos sefardíes se dirigieron al noroeste de Europa, al norte de África, al territorio del antiguo Imperio Otomano y, hacia donde fue la comunidad, fue también el idioma. Por eso, los propios hablantes llamaban a su idioma espaniol o espaniol muestro e iban adoptando lenguas habladas en los territorios del exilio. En Marruecos se puede encontrar una variante influida por el árabe marroquí y desde el siglo XX, también por el francés, que se llama haketía; en el territorio del antiguo Imperio Otomano se usa el término judezmo afectado tanto por el turco como por el griego y lenguas eslavas dependiendo de la región exacta (GARCIA, 2007: 88). En la presente comunicación vamos a usar el término judeoespañol que cubre todas las variantes del idioma hablado y, al mismo tiempo, hace referencia a las dos culturas que le dieron la luz, mientras que el ladino lo dejamos al contexto de las traducciones oficiales de los textos sagrados, según más arriba.

Hoy en día se puede hablar de unas 50.000 hasta $200.000^{1}$ personas que conservan el idioma judeoespañol, siendo hablantes u oyentes. La comunidad más grande actualmente vive en el Estado de Israel, pocos hablantes se encuentran también en Bosnia, Serbia, Macedonia, Bulgaria o Turquía, aunque es importante mencionar que en el período de entreguerras se produjo una migración muy fuerte a Argentina, Chile y México donde, naturalmente, el idioma fue absorbido muy rápido por el español. El peligro de extinción se debe, ante todo, al hecho de que los conservadores de la lengua son personas muy mayores cuyos descendientes posiblemente ya no la preserven (VENTAS, 2017).

Resulta paradójico que hoy en día haya tan pocos hablantes del idioma y tantos activistas por parte de los investigadores y académicos que lo deseen rescatar. «El judeoespañol es una lengua maravillosa que hoy debería emocionar a cualquier hablante del idioma español», afirmó el director de la Real Academia Española (RAE), Darío Villanueva, en una entrevista para BBC Mundo (VENTAS, 2017). Siendo emocionados por el idioma, los académicos israelíes y españoles empezaron a averiguar posibilidades de salvarlo. Sus esfuerzos desembocaron en el año 2018 en la fundación de la Academia Nacional del Judeoespañol en Israel. Dicha Academia se debería dirigir a la preservación de la lengua judeoespañola como una herencia lingüística y cultural no solamente judía, sino también hispana. El vínculo con España se acentúa aún más en el hecho de que dicha Academia forme parte de las veinticuatro Academias de la lengua española y, posiblemente, se incorpore a la Asociación de Academias de la Lengua Española (RAE, 2018).

\footnotetext{
${ }^{1}$ Hay que subrayar que las estimaciones varían mucho, incluso se pueden encontrar datos sobre 500.000 personas dispersas por el mundo que utilizan de forma activa o pasiva el judeoespañol. Disponible en: http://blog.cervantesvirtual.com/academia-nacional-del-judeoespanol/
} 
Hablando de los esfuerzos dirigidos hacia la preservación de la lengua judeoespañola como parte de la hispanidad, hace falta mencionar los intentos de devolución de la nacionalidad española a los descendientes de los judíos sefardíes expulsados de España en el siglo XV. Los orígenes de la ley de concesión de la nacionalidad española a los sefardíes se deben al año 1868, cuando el General Prim avisó a los judíos, «Son libres de entrar en nuestro país y ejercer libremente el culto, así como a los miembros de todas las religiones» (SFARAD, 2019). En 1924 el Directorio Militar de Primo de Rivera aprueba la concesión de la nacionalidad española a protegidos de origen español a los que pertenecían también los judíos sefardíes. Entonces, los interesados tenían un plazo de seis años para solicitar la nacionalidad, sin embargo, pocos de ellos (unos 5.000) expresaron su interés. Por fin, en el año 2015 se aprobó una nueva ley cuyo plazo de solicitud se cerró el 31 de agosto de 2019. Esta vez, unas 132.000 personas de origen judeoespañol presentaron su solicitud, el mayor número de ellos procedente de México (30.000), seguido por Colombia (26.000), Venezuela (14.000), Argentina (7.000), EE.UU. (más de 5.000) e Israel (casi 5.000). El presidente de la Federación de Comunidades Judías de España, Isaac Querub concluyó, «Los sefardíes ya no son españoles sin patria» (GONZÁLEZ, 2019).

Dicho eso, está claro que, desde el punto de vista internacional, el tema de la cultura judeoespañola capta mucha atención recientemente; sin embargo, en el territorio checo no se ha acentuado, por ahora. Hasta el momento el idioma judeoespañol ha sido objeto de estudio de varios trabajos de graduados referidos a los problemas lingüísticos; no obstante, carecemos de análisis de textos judeoespañoles en el ámbito checo. Hay una ausencia absoluta de monografías que se dediquen a la presencia del judeoespañol en nuestro territorio, a la relación entre el checo y el judeoespañol o a los problemas de su traducción. El tema presenta un vacío en el contexto de la historia de las traducciones checas de la literatura española. Motivados por la actividad de la RAE en este asunto, podemos abrir un nuevo espacio de investigación que traiga el tema al público checo. Como se trata de cuestiones poco conocidas o incluso desconocidas, se ofrece comenzar investigando en el área de la historia de la traducción.

\section{Traductólogo como historiador}

Si un traductólogo investiga en el área de la historia de la traducción, tiene dos tipos de fuentes: textos publicados que se pueden encontrar en bibliotecas y materiales de archivo. Los traductólogos, generalmente, trabajan con textos publicados, es decir, con traducciones que analizan, no obstante, es importante darse cuenta de que mucha información relevante se puede ganar también de los peritextos (los prólogos, los epílogos, las notas del traductor, etc.). Más información aún se puede obtener de los paratextos, como son los planes de edición. Por último, el contexto de la cultura recipiente se manifiesta en metatextos, como son reseñas de la traducción, artículos sobre el autor del documento y sobre la literatura y la cultura original (STřEDOVÁ, 2019: 94).

Los traductólogos generalmente acuden a los materiales de archivo cuando necesitan contextualizar o comprobar sus conocimientos ganados en un análisis 
textual previo. En la República Checa se pueden encontrar archivos públicos y privados. Al primero grupo pertenece el Archivo Nacional y los archivos regionales y provinciales, que guardan documentos como registros civiles o documentación vinculada a las instituciones y las empresas desaparecidas; el Archivo de Cuerpos de Seguridad, dirigido por el Ministerio del Interior; y archivos especializados, por ejemplo, de los cuerpos de organización del estado, como son el Parlamento, el Senado, las universidades, el Museo Nacional, etc. (STŘEDOVÁ, 2019: 95).

Dentro del segundo grupo están los archivos de personas jurídicas (teatros, editoriales) y también documentos que poseían individuales ya fallecidos, si los gestionan sus familiares. Sin embargo, archivos personales también se pueden depositar y administrar en instituciones especializadas. Aquí existe mayor posibilidad de encontrar correspondencias, manuscritos, etc. Hay una gran diferencia entre el trabajo de investigación en los archivos públicos y personales. Teniendo leyes que arreglan las condiciones del uso de los archivos, el caso de los archivos personales siempre supone comunicación con los parientes del difunto, $y$ además, el nivel de tratamiento y procesamiento de los materiales varía mucho (STŘEDOVÁ, 2019: 95).

Primero hace falta averiguar en qué institución se encuentran los documentos relevantes. Hoy en día existe la posibilidad de aprovechar los buscadores online, como es el portal de los documentos de archivo y colecciones de la República Checa, por ejemplo. En las páginas web del archivo correspondiente se puede encontrar directamente el documento necesitado (si es que fue digitalizado) o contactar el archivo y pedir el préstamo de los documentos de acuerdo con el reglamento de investigación que, por supuesto, puede variar según cada institución (STŘEDOVÁ, 2019: 96).

Una vez conseguidos los materiales, el investigador puede trabajar como traductólogo y usar distintos métodos del análisis textual. Además de eso, el documento debería estar sometido bajo un análisis histórico que permitiera comprobar la autenticidad del material, su datación, la autoría, etc. Luego viene una crítica interna enfocada en la valoración del contenido (crítica textual) y, al final, una interpretación. Aquí se puede observar que el traductor de repente se convierte en un historiador usando los métodos de investigación propios para los historiadores. Aprende, por ejemplo, cómo consigue el material de archivo que posteriormente somete bajo un análisis crítico e interpretación. Las fuentes de archivo pueden ayudar a intercalar el conocimiento a un contexto más amplio. Teniendo ese material, el investigador puede preguntarse, cuál fue la motivación de la traducción o cuál es la función del texto traducido, en qué contexto nació y por último, cómo fue recibida (STŘEDOVÁ, 2019: 100-101).

\section{Material disponible}

\section{1. Canciones sefardíes}

Tras una consulta de los catálogos de bibliotecas, se descubre que se ha manifestado en nuestro país un interés significativo por las canciones sefardíes. La Biblioteca Municipal de Praga dispone de nueve discos de canciones sefardíes y tres de ellos vienen acompañados por un booklet de transcripciones de las canciones 
sefardíes con sus respectivas traducciones al checo, en dos casos también al inglés. En 1993 aparece en el mercado checo el CD de Jana Lewitová y Rudolf Měřinský llamado Sephardic Songs. El disco viene acompañado por un booklet de veintitrés páginas en el que se encuentran veintidós canciones judeoespañolas transcritas y traducidas al checo y al inglés; una introducción checa con su respectiva traducción al inglés que desplaza al lector a España del siglo XV; y las últimas páginas están dedicadas a los perfiles de los intérpretes. Efectivamente, según las afirmaciones dadas arriba, se puede ganar mucha información de los peritextos:

a) dan cierta imagen del contexto temporal y del lugar en el que nacieron las canciones: los Reyes Católicos expulsan del país a la comunidad judía, cuyo idioma y canciones, sin embargo, se conservan en la zona del Mediterráneo durante más de quinientos años hasta hoy;

b) los intérpretes explican el fondo de su formación musical y consecuentemente la motivación para preparar el disco.

Hablando en la terminología de Christiane Nord, los peritextos del booklet dan la información completa sobre los factores extratextuales.

En cuanto al contenido y a la traducción al checo (y en consecuencia al inglés), es posible afirmar que tiene carácter puramente documental. El siguiente ejemplo apoya la presente afirmación:

Canción Ven querida en judeoespañol:

«Ven querida, ven amada,/ Ven al borde de la mar, aman, ama./ Ven te contaré mis males,/ Que te metas a llorar./ Huérfano de padre y madre,/ Yo no tengo onde arrimar./ Hazere un buen sueño,/ En tus brasos muereré».

Traducción al checo:

«Milá, pojd' na mořský břeh,/ povím ti o svém neštěstí./ Sladkým spánkem usnu,/ v tvém náručí zemřu...»

Traducción al inglés:

«Come to the seashore, my love,/ And I will tell you my sorrow,/ Sweetly will I fall to sleep,/ And die in your embrace» (LEWITOVÁ, MĚŘINSKÝ, 1993: 12).

Basándose en este ejemplo se puede afirmar que se trata de una traducción documental en la concepción de Christiane Nord. ${ }^{2}$ La traducción, preparada por la intérprete, no aspira a tener un valor artístico. Lo mismo ocurre con el disco Sephardic Inspiration en el que trabajó la misma cantante Jana Lewitová con el director de cine y compositor Vladimír Merta. Incluso los peritextos tienen un carácter muy similar, aunque en este caso desarrollan un poco más la teoría e historia musical.

La cuestión que se ofrece en este momento es: ¿existen más traducciones checas del judeoespañol, hay traducciones checas literarias o artísticas tanto de las

\footnotetext{
${ }^{2}$ «Two different types of translation - documentary and instrumental (Nord, 1991, p. 72) - may serve as an example of the connection between the text function and a translation. The more frequent instrumental translation represents conveyance of a message from a ST [Source Text] author to a TT [Target Text] recipient directly, whereas the documentary translation is only a document of the communication between a ST author and a ST recipient». (POBOČíKOVÁ, 2012: 23)
} 
canciones sefardíes, como de otros textos? Estas preguntas llevan a la investigación en materiales de archivo.

\section{2. Trabajos de graduados}

Cierto material y unas buenas pistas para empezar la investigación de archivo están escondidas en los trabajos de graduados, ante todo en los trabajos lingüísticos defendidos en las Facultades de Filosofía y Letras de la Universidad Carolina y la Universidad Masaryk. Naděžda Moučková de la Universidad Carolina defendió en el año 2008 la tesis Sefardské texty ve vídeňském archivu. En el trabajo la autora describe, por un lado, la industria editorial de los textos judeoespañoles en Viena; por otro lado, transcribe la obra Don Yosef y su hija y comenta el texto sefardí. La autora no solamente comenta el texto, sino que también lo cita en checo. Desde el punto de vista de la investigación, la traducción presenta cierto material con el que hay que trabajar: las traducciones judeoespañolas hechas por motivos de los trabajos de graduados. Además, la tesis facilita una información relevante acerca de la investigación de archivo: habla sobre la imprenta de textos judeoespañoles ubicada en Bratislava. Aquí es posible suponer cierta relación con el idioma eslovaco y se puede empezar a investigar en dicha área. Transcripción del judeoespañol, en concreto de su variante hablada en Salónica, se encuentra también en la tesis de Kateřina García de la Universidad Carolina Aspekty soluňské varianty judeošpanělštiny. Aparte del desarrollo histórico del idioma y de las transcripciones mencionadas se observan en el trabajo palabras traducidas, o sea que también supone material interesante.

Junto con Bratislava es de esperar material interesante en los archivos y bibliotecas de Sarajevo y Zagreb. En 2010 escribió Lenka Volfová, estudiante de la Universidad Masaryk, una tesina llamada Sefardští Židé v Sarajevu que hace referencia a la iniciativa estudiantil Esperansa fundada en 1924 por estudiantes de Bosnia que habían venido a estudiar a Zagreb. La esfera académica permitía encuentros de los estudiantes bosnios con sus colegas de otros países como Austria, Italia, Francia y también Checoslovaquia. Dicha iniciativa disponía de una gran biblioteca llamada Biblioteca sefardica que incluía muchos volúmenes en el judeoespañol.

\section{Material potencial}

Un material potencial e interesante se podría encontrar en las herencias de dos personajes praguenses, poliglotas el profesor Pavel Trost y el escritor Jiř́i M. Langer. Pavel Trost era uno de los miembros del Círculo lingüístico de Praga, un gran lingüista que publicaba estudios sobre el checo, el alemán, las lenguas eslavas o bálticas y también se encuentran en su trabajo contribuciones sobre el griego, el latín, el búlgaro, el rumano, el persa, el romaní o el judeoespañol. Asimismo, era un experto de formato internacional en otra lengua propia a la comunidad judía: el yidis (ČERMÁK, 2010: 6). Según la tesina de Denisa Garciová de la Universidad Carolina $Z$ díla Jiř́ho Mordechaje Langera: Básnická sbirka Pijutim ve-širej jedidut es de encontrar elementos judeoespañoles y sefardíes al nivel temático y lexical en la obra de Jiř́i M. Langer (GARCIOVÁ, 2012: 61). 
El espectro de instituciones donde se puede encontrar material judeoespañol relacionado con el idioma checo llega hasta el Archivo de la música de películas checas y eslovacas. Jiř́ Šust, compositor destacado y autor del acompañamiento musical de doce películas de Jiří Menzel, compuso en 1975 una representación de televisión llamada Titul pro hrdinu. La letra de las canciones incluidas en este programa viene en el judeoespañol. Por lo tanto, es de suponer que en la herencia del autor o en el archivo mencionado pueda estar depositado algún material unido a dicho proyecto.

Excepto las instituciones mencionadas, los puntos de partida para la investigación en el área de las traducciones checas del judeoespañol son el Archivo del Museo Judío de Praga, los archivos y documentos de la Federación de las Comunidades Judías en la República Checa o el Instituto Cervantes de Praga. Las primeras dos instituciones disponen de un material muy amplio vinculado a la historia de la comunidad judía en el territorio checo. Aunque la presencia de la comunidad sefardí nunca fue significative en este país, es posible encontrar en la historia de los judíos en las tierras checas ciertos momentos o personajes cuyos documentos podrían enriquecer la investigación. Por ejemplo, se sabe que en la segunda mitad del siglo XIX ocupó la posición de rabino en la ciudad de Písek (Bohemia) Mordejay Grünwald, nacido en Hradisch (Moravia). Grünwald estudió en Wroclaw y además de Písek fue rabino en Belovar (Croacia) o Sofía, fue historiador y lingüista que escribía tanto en el alemán, como en el judeoespañol. Unos doscientos años antes se instaló en Nikolsburg (Moravia) Moshe ben Mijael Hakohén, cantor sinagogal nacido en Salónica o Sarajevo y luego trasladado a Sofía y Belgrado.

\section{Conclusiones, observaciones finales}

En las últimas décadas la traductología abrió sus puertas hacia cambios metodológicos y nuevos campos de interés, siendo una disciplina integrada científica. Históricamente, pertenecían los países checos a la región cultural ashkenazí cuya población judía utilizaba hebreo (o arameo), al mismo tiempo, adaptaba la lengua de la sociedad mayoritaria y, por último hablaba, yidis. La lengua judeoespañola, por lo tanto, presenta un vacío grande en la historia de las traducciones checas. Se trata de una lengua marginada hasta hace poco no solamente en el territorio checo, sino también en el mundo. No obstante, gracias a la fundación de la Academia Nacional del Judeoespañol en Israel despierta interés internacional por el tema. Incorporar la problemática de las traducciones checas del judeoespañol a la traductología checa significa adoptar los procesos de investigación propios de los historiadores, ya que carecemos de monografías dedicadas al tema. El traductor tiene que trabajar con fuentes históricas, archivalias, que, además del mensaje lingüístico pueden dar testimonio de la situación social, traductológica o editorial de la época estudiada. Por una parte, la traductología puede apropiarse la metodología de investigación histórica $y$, por otra parte, es capaz de enriquecer a través de las traducciones de las fuentes a otras disciplinas científicas.

Volviendo al judeoespañol como un idioma de los judíos sefardíes, hay que tener en cuenta su aspecto cultural. Hablar sobre la cultura sefardí en el contexto 
checo significa enfrentar a dos sistemas distintos en cuanto a la lengua, sociedad y también geografía, donde el traductor representa el puente de comunicación entre las dos culturas. «La tarea de traducir ha ido siempre paralela a la epistemología de una época, a las culturas, a las sociedades y a todos los cambios filosóficos, artísticos y científicos que han influido en el ser humano. Todo influye en la traducción, que no es una labor ajena a nada» (ÁFRICA VIDAL ClARAMONTE, 2009: 51). No cabe olvidar que «la traducción es siempre reflejo del tipo de sociedad que la genera» (ÁFrICA VidAl ClARAMONTE, 2009: 51). La investigación del tema, por lo tanto, contribuye al desarrollo del testimonio y autorreflexión de nuestra propia sociedad, cultura e historia.

\section{BIBLIOGRAFÍA}

ÁFrica Vidal Claramonte Carmen M (2009), A vueltas con la traducción en el siglo XXI, MonTI, nº 1, p. 49-58. ISSN 1989-9335.

ČERMÁK Jan (2010), Pavel Trost a jeho celostní filologie. Časopis pro moderní filologii [online], 2010, $\mathrm{n}^{\circ} 92$ [cit. 2019-04-25]. ISSN 2336-6591. Disponible en: http://www.mluvniceanglictiny.cz/system/files/Pavel\%20Trost $\% 20 \mathrm{a} \% 20 \mathrm{je}$ ho\%20celostn $\% \mathrm{C} 3 \% \mathrm{AD} \% 20$ filologie $\% \mathrm{C} 4 \% 8 \mathrm{Cerm} \% \mathrm{C} 3 \% \mathrm{~A} 1 \mathrm{k}$.pdf

GARCIA Kateřina (2007), Aspekty soluňské varianty judeošpanělštiny, Praga, 2007. Tesis doctoral. Universidad Carolina, Facultad de Filosofia y Letras, Departamento de romanística, Lenguas romances - español.

GARCIOVÁ Denisa (2012), $Z$ díla Jiřiho Mordechaje Langera: Básnická sbírka Pijutim ve-širej jedidut, Praga, 2012. Tesina de máster. Universidad Carolina, Facultad de Filosofía y Letras, Departamento de literatura checa y ciencia literaria.

GONZÁLEZ Miguel (2019), “Los sefardíes ya no son españoles sin patria”, proclama el presidente de la comunidad judía, in: El País [online], Oct 2, 2019 [cit. 201911-20]. Disponible en: https://elpais.com/politica/2019/10/02/actualidad/1570019211_938436.html

La nacionalidad española de los sefardies, 2019 [online]. Sfarad. [cit. 2019-11-20]. Disponible en: https://www.sfarad.es/la-nacionalidad-espanola-de-lossefardies/

LEWITOVÁ Jana, MĚŘInskÝ Rudolf (1993), Sephardic Songs [CD], Praga, ARTA Records.

MouČKOVÁ Naděžda (2008), Sefardské texty ve vídeňském archívu, Praga, 2008. Tesina de máster. Universidad Carolina, Facultad de Filosofía y Letras, Departamento de romanística.

PoBoČíKOVÁ Pavlína 2012), Changes in a Source Text during Repeated Translation, Brno, 2012. Tesina de máster. Universidad Masaryk, Facultad de Filosofía y Letras, Departamento de estudios ingleses y americanos.

Se acuerda la creación de la Academia Nacional del Judeoespañol en Israel, 2018 [online], RAE. [cit. 2019-11-20]. Disponible en: https://www.rae.es/noticias/seacuerda-la-creacion-de-la-academia-nacional-del-judeoespanol-en-israel 
STŘEDOVÁ Kateřina (2019), Archivní prameny v translatologickém výzkumu - kde je hledat a jak s nimi pracovat? AUC Philologica, $\mathrm{n}^{\circ}$ 1, p. 93-106. ISSN 05678269.

VENTAS Leire (2017), Qué es el ladino, el idioma "en peligro de extinción" al que se quiere dedicar una academia de la RAE para solventar una "deuda histórica", in: BBC Mundo [online], Sep 24, 2017 [cit. 2019-11-20]. Disponible en: https://www.bbc.com/mundo/noticias-41348482

Volfová Lenka (2010), Sefardští Židé v Sarajevu, Brno. Trabajo de grado. Universidad Masaryk, Facultad de Filosofía y Letras, Departamento de estudios eslavos, Estudios balcánicos. 